\title{
Mothers' perceptions of their premature infant's communication: A description of two cases
}

\author{
Michelle Pascoe*, Divya Bissessur, Pat Mayers \\ University of Cape Town, Department of Health and Rehabilitation Sciences, F45 Old Main Building, Groote Schuur \\ Hospital, Observatory, 7925 Cape Town, South Africa
}

\section{A R T I C L E I N F O}

Article history:

Received 3 February 2015

Accepted 7 October 2015

Available online 22 March 2016

Keywords:

Premature infants

Communication

Qualitative

\begin{abstract}
A B S T R A C T
Background: Survival rates of premature infants have increased due to advances in medicine. Premature infants however, remain at risk for developmental delays including communication difficulties. The bonding and attachment experiences of premature infants and their parents are often challenged, further placing these infants at risk for communication difficulties. This study firstly aimed to explore mothers' perceptions of their premature infants' communication. The second aim was to explore the mothers' perceptions of their own role in the communication development of their infants.

Methods: A descriptive, longitudinal study was conducted with two mother-infant dyads. Three visits took place in the first year of life. Subjective maternal reports were obtained through semi-structured interviews.

Results: Differences in the two mothers' perceptions were noted. The mothers described helping their infants to communicate through physical contact and talking. Risk and protective factors for early communication development are discussed in relation to the findings.

Conclusion: The findings support the need for a healthy mother-infant relationship in the first few months of life. Health professionals should support premature infants and their families after discharge in order to help them interact with their infants and encourage attachment and bonding.
\end{abstract}

(C) 2015 The Authors. Publishing services by Elsevier B.V. on behalf of Johannesburg University. This is an open access article under the CC BY-NC-ND license (http:// creativecommons.org/licenses/by-nc-nd/4.0/).

\section{Introduction}

Advances in technology have resulted in increased survival of preterm infants. More babies are surviving at younger gestational ages and with lower birth weights (WHO, 2014). Improved survival has led to an increase in subsequent neurodevelopmental difficulties, as infants with younger gestational ages are at higher risk of having medical complications.
In South Africa, health and economic factors mean that premature babies are even more likely to be at risk of developmental delays. This paper focuses on premature infants, defined as being born before 37 weeks gestation, and their early development of communication as perceived by their mothers, in the South African context. We apply a broad definition of communication, as being the sharing of intended meaning by two or more individuals, following Rossetti (2001).

* Corresponding author. Tel.: +27 214066043.

E-mail address: michelle.pascoe@uct.ac.za (M. Pascoe).

Peer review under responsibility of Johannesburg University. http://dx.doi.org/10.1016/j.hsag.2015.10.002

1025-9848/@ 2015 The Authors. Publishing services by Elsevier B.V. on behalf of Johannesburg University. This is an open access article under the CC BY-NC-ND license (http://creativecommons.org/licenses/by-nc-nd/4.0/). 
Having a premature infant can have a major impact on the quality of the child-parent relationship for a number of reasons. Firstly, infants cannot respond to parental expectations in the same way that full-term babies do. They tend to be less alert and responsive (Montirosso, Borgatti, Trojan, Zanini, \& Tronick, 2010; Tallandini \& Scalembra, 2006). Secondly, mothers typically feel unprepared due to the early birth, which challenges the attachment process (Borghini et al., 2006). They face the stress of their baby being placed in the neonatal intensive care unit (NICU) immediately following birth. Parents have described the NICU as overwhelming and frightening (Leonard \& Mayers, 2008). Thirdly, mothers themselves are at higher risk of exhibiting depressive symptoms in response to the stress of having a premature infant (Veddovi, Kenny, Gibson, \& Starte, 2001). Depressed mothers show less positive parenting and have more difficulties in interpreting their infant's behaviours (Singer et al., 2003). Kritzinger and Louw (2003) described how some mothers of premature babies believed their infants were not able to see and hear at birth and were thus not responsive to their babies. In some cases, mothers were scared to bond with their babies in case they did not survive (Leonard \& Mayers, 2008). Lastly, premature infants are at risk of presenting with feeding difficulties. Mothers of premature infants with feeding difficulties often perceive interactions during feeding to be negative and frustrating (Swift \& Scholten, 2009).

The transactional model has been used to describe the impact of interactions on the development of a child (Sameroff \& Fiese, 2000). The model describes how the way in which the caregiver interacts with the child influences the nature of the child's response, and the way in which the child interacts with the caregiver influences the caregiver's response (Keilty \& Freund, 2005). It emphasizes that each child's development is influenced by unique risk and protective internal and environmental factors.

Perception of child vulnerability has been shown to have an impact on developmental outcomes at one year of age. Allen et al. (2004) suggested that parents often perceive their premature infants to be more vulnerable when compared to full-term peers. They may shelter their infants more, and provide fewer opportunities for them to become independent. Mothers of premature infants also provide less support, use a lower quality of vocalisations and choose less age-appropriate toys for their infants (Porter, Stern, \& Zak-Place, 2009). The perception that their infants are vulnerable makes parents provide less positive interactions and fewer learning opportunities, which could in turn negatively impact the child's development.

Suttora and Salerni (2011) describe how mothers' communicative styles changes over time. Maternal speech was analysed for lexical and syntactic complexity and verbal productivity when preterm infants were 6, 12, 18 and 24 months corrected age, as well as the infants' communicative, motor and cognitive abilities. Maternal verbal input did not differ compared to term infants at those ages, showing that mothers of preterm infants provide the same type of verbal input. It was however noted that changes in verbal input were more influenced by the child's verbal and motor development. Preterm infants' motor skills and verbal output represented a cue for mothers to adjust their communicative style, showing the dynamic interplay between infants' development and mothers' interactions.

The lack of or inadequacy of interaction between parents and a child can impair the establishment of bonding and attachment, which in turn can impact on the child's social, emotional, cognitive and language outcomes (Muller-Nix et al., 2004). Environmental factors can either serve as a protective or risk-perpetuating mechanism in the child's development. For these reasons, premature infants are at risk of facing difficulties with the earlier aspects of communication development. Fig. 1 shows how the transactional model can be applied to the developmental outcomes of premature infants.

Prematurity can contribute to communication difficulties that present from the first year of life and sometimes persist into the school years. Preterm infants have been reported to show poorer language comprehension and expression including vocabulary and narrative (Briscoe \& Gathercole, 2001; Limperopoulos et al., 2008). Prevalence of hearing loss is higher in this population, and can negatively affect other areas of communication. Premature infants without neurological disabilities may also show signs of communication difficulties (Crosbie, Holm, Wandschneider, \& Hemsley, 2011). The association between prematurity and communication difficulties involves a complex interplay of influences between the child and his/her environment (Lewis et al., 2002).

The Rossetti Infant Toddler Language Scale (Rossetti, 2005) is a criterion-referenced scale that used by Speech and Language Therapists (SLTs) and other health professionals to assess communication and interaction in children from 0 to 36 months. It focuses on: interaction-attachment, pragmatics, play, language expression and comprehension. Interaction-Attachment refers to the reciprocal relationship between caregiver and infant (Rossetti, 2005), e.g. a mother making eye contact in response to her child crying, which

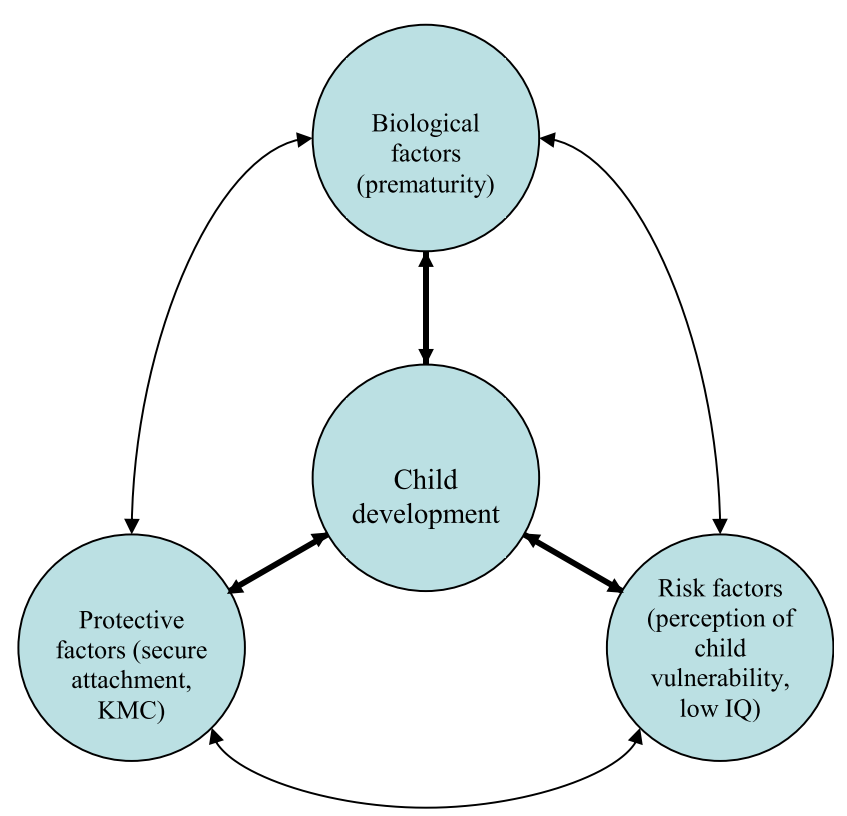

Fig. 1 - The transactional model applied to developmental outcomes in prematurity. 
results in soothing the child. Pragmatics is the child's use of language within a social context, e.g. an infant produces a 'hunger cry' for a specific purpose. Play refers to activities for no specific purpose but which may reflect development of representational thought (Rossetti, 2005), e.g. banging of objects. Language expression refers to the production of preverbal and verbal language. Comprehension is the understanding of language. Specific behaviours may either be directly observed, reported by carers or elicited. The scale has been widely used in clinical practice and research focussing on the development of young children (Bairati et al., 2011; Leigh, Dettman, Dowell, \& Briggs, 2013; Van Rie, Mupuala, \& Dow, 2008).

The present study aimed to explore mothers' perceptions of their low risk low birth weight infant's communication while including a focus on the interaction patterns in the early months of life between the mother-infant dyads. The first aim of this study was to describe the mothers' perceptions of their premature infant's communication. The second was to describe the mothers' perceptions of their role in the communication of their premature infants.

\section{Methods}

\subsection{Design}

The study used a qualitative approach to investigate the nature of the mothers' perception of communication within the dyad. The study was longitudinal with the dyads followed over a 6-month period within the first year of the infant's life. Each dyad was visited on three occasions: T1: one week post discharge from NICU; T2: three months corrected age; T3: six months corrected age. Corrected age refers to the age from the expected date of birth.

\subsection{Participants}

This research included two mother-infant dyads. Their background information is presented in Tables 1 and 2. All participants' names have been changed.

After obtaining approval from the University's Research Ethics Committee and the facilities concerned, the recruitment process began. Mothers and infants were recruited from public and private health facilities in Cape Town using a mediated access approach. A health professional at each facility assisted in obtaining the details of potential participants. Posters were placed in the breastfeeding and Kangaroo Mother Care rooms providing details about the study. Mothers were invited to participate in the study if they met the inclusion criteria. They were asked to give their contact details to the designated contact at that facility. The researcher briefed the contact person so that they could also verbally inform potential participants about the study. This was done to ensure that mothers who were illiterate could also take part in the study.

The preterm children were required to have a gestational age of less than 37 weeks and birth weight between $1500 \mathrm{~g}$ and 2500 g. They did not present with any major neurological, physical, congenital or sensory difficulties. Mothers were required to live with their infants and be the primary caregivers. The participants were the first dyads who met the inclusion criteria and where the mothers gave informed consent to participate.

\subsection{Materials and procedure}

Otoscopy and OtoAcoustic Emission testing (Viasys Healthcare AABR and OAE combination machine: AO040256) were carried out. Three semi-structured interviews were carried out with the mothers at T1, T2 and T3. A different interview schedule was used each time to minimize conditioning effects (see Appendix 1). Interviews lasted for approximately one hour and were conducted at the participant's house. Each schedule was based on the developmental milestones expected to occur over time with questions encompassing the areas of the Rossetti Infant Toddler Language Scale.

A video recorder (Panasonic I6SA11870 R) and dictaphone (Cenix VR-W2402GB) recorded information for later review. The video recording was used to capture interaction between mother and child, and was used to ensure that the researcher could review what had taken place in the interview session without missing any details. A research assistant viewed $10 \%$ of the recorded data to ensure that the observations made by the main researcher had been accurately captured, which strengthened the credibility of the study.

Field notes were taken and following the visits, more detailed notes were made. The recorded data was reviewed, transcribed and analysed using conventional content analysis. The five steps for qualitative data analysis described by Terre-Blanche, Durrheim, and Painter (2006) were followed. These included:

a) Familiarisation and immersion. All recordings were transcribed by the main researcher. This provided an opportunity to be fully immersed in the data, which could potentially generate insights for the analysis. The researcher repeatedly read the transcribed data as a whole from beginning to end to achieve immersion.

b) Inducing themes. Categories were labelled by highlighting words or phrases from the text that appeared to capture key thoughts or concepts. Categories were then organised into chronological themes, which were then rearranged into main themes with underlying subthemes.

c) Coding. This refers to marking different sections of the data as being relevant to one or more themes. This was

Table 1 - Background information of mothers.

\begin{tabular}{lclccc} 
Mothers & Age (years) & \multicolumn{1}{c}{ Education level } & Occupation & Marital status & Other children \\
\hline Abigail & 18 & First year of technical college & Student & Single & None \\
Beverly & 33 & Tertiary education & Teacher & Married & 2 \\
\hline
\end{tabular}


Table 2 - Background information of babies.

\begin{tabular}{llcccc} 
Infants & Sex & Gestational age (weeks) & Birth weight (g) & Hospitalisation (days) & Recruitment \\
\hline Anathi & Male & 33 & 2050 & 10 & Public hospital \\
Blair & Female & 33 & 1900 & 21 & Private hospital \\
\hline
\end{tabular}

undertaken using different coloured pens to highlight the different codes.

d) Elaboration. The researcher went back and forth between the whole texts, the themes and the codes developed. This process was continued until no new insights emerged.

e) Interpretation and Checking. The final stage of analysis involved providing a written account of the phenomena studied. The researcher reviewed the data, removed sections that seemed to be irrelevant and reflected on and documented the impact that her presence might have had on the data collection and analysis process. During this step, an assistant researcher also reviewed a portion of the transcribed data and disagreements were discussed until consensus was reached.

This study received approval from the University's Human Research Ethics Committee. Mothers were required to give informed consent for their own and their children's participation in the study. They gave explicit permission for the video-recordings to be taken. The research term ensured that participants' anonymity and confidentiality were maintained throughout. Trustworthiness of this study was managed in several ways. Prolonged engagement with research participants in their own homes ensured greater credibility. Member checks were carried out through clarification of misunderstandings with the mothers. At the end of each visit, summarised observations were given to the mothers and they were asked to confirm that what the research team understood was correct. An audit trail documented the research process in detail.

\section{Results}

\subsection{Background information}

\subsubsection{Case study 1: Abigail and Anathi}

Abigail is an 18-year-old female living in low-cost housing in Cape Town. After going for a routine check-up at the community clinic, she was diagnosed with HELLP syndrome (Hemolytic anemia, Elevated Liver enzymes and Low Platelet count) leading to renal dysfunction. She was admitted to hospital where she had a Caesarean section delivery. Her first baby, Anathi, a boy, was born at 33 weeks of gestation weighing $2050 \mathrm{~g}$. Abigail's first language is isiXhosa, but she also speaks English fluently. Abigail lives with her aunt, nephews and nieces in a two-roomed house. At the third visit (T3), Abigail had started attending college. Her aunt looked after Anathi during the day.

After birth, Anathi was placed in an open cot and was fed infant formula orally through feeding tubes. Abigail was not able to have any physical contact with him for one week postdelivery while he underwent phototherapy. He was tube-fed during this initial period. Abigail started Kangaroo Mother Care (KMC) after one week and began cup and breastfeeding Anathi at this time, as his feeding tube was removed. She stayed in the hospital with her son until he was discharged, about ten days after birth. This meant that she was only able to hold and interact with him for three days prior to him leaving hospital.

Abigail felt unprepared for Anathi's early birth and was scared about his medical and developmental status. She lacked information about the medical condition of her baby, and would have liked more information about the feeding tubes and the reason why she could not breastfeed till she started KMC. Abigail explained that she would have liked to receive more support from the staff at the hospital but instead turned to her family to help her with breastfeeding.

\subsubsection{Case study 2: Beverly and Blair}

Beverly is a 33-year-old female living in Cape Town, with her husband and three daughters. Her third daughter, Blair, was born at 33 weeks gestational age with a birth weight of $1900 \mathrm{~g}$. Beverly had been hospitalised at 33 weeks due to a placental abruption. She was admitted to a private hospital in Cape Town where an emergency Caesarean section delivery was performed. Beverly is a teacher and speaks English at home with her family. Her other daughters are three and six years old respectively.

Beverly was able to hold Blair shortly after birth, before she was admitted to the NICU. Beverly stayed in the hospital for three days, while Blair stayed in the NICU until she was discharged, about three weeks after birth. During her stay in hospital, Blair underwent phototherapy for jaundice and was connected to a C-pap machine to assist with breathing for the first four days after birth. Afterwards, she was placed in an incubator for one day, before moving into an open bassinette. Blair was fed through feeding tubes orally while she was on the C-pap machine, and nasally afterwards. A week before being discharged, she started being bottle fed and was thus able to leave hospital able to feed orally and with no need for any feeding intervention. Beverly and her husband were able to hold Blair once she was off the C-pap machine. After being discharged, Beverly would visit Blair at the hospital once or twice daily. Beverly tried to practice KMC for about an hour everyday from there onwards. After Blair was discharged from hospital, Beverly would still place her on her chest, but not necessarily practice skin-to-skin contact.

Beverly was very shocked and upset when she found out that she needed an emergency delivery. She was also worried that Blair might have medical problems. Beverly reported feeling guilty for not being able to spend much time with Blair while she was in hospital, as she also needed to care for her other children at home. Blair exhibited some aversion to touch for the first few days after birth. She cried and became distressed when touched by anyone. Beverly felt that Blair's 
aversion to touch together with the complexities of holding a premature baby in an NICU made the bonding process for her and her husband difficult. She was not able to bond with Blair while she was in hospital as she spent considerable time sleeping. Beverly did report that Blair was more relaxed during $\mathrm{KMC}$ and this helped them slowly start bonding.

\subsection{Aim 1: Mother's perceptions of her infant's communication}

This section has information grouped under the five areas of the Rossetti Infant Toddler Language Scales. Key information relating to each subsection is described and illustrated with quotes from Abigail and Beverly. The time of the visits have been indicated in brackets after each quote (T1: one week post discharge from hospital; T2: three months corrected age; T3: six months corrected age).

\subsubsection{Interaction-attachment}

Both mothers reported that initially their infants were very sleepy and this made interacting a challenge.

Abigail: "He sleeps a lot, I don't like that. I want him to be awake, when I breast feed him he is also sleeping ..." (T1).

Activity levels started to gradually increase. Shortly after being discharged, Abigail felt that she developed a sense of reciprocity with Anathi where they would understand each other's actions.

Abigail: "He knows I am changing him, he moves around" (T1).

Similarly, at T1, Blair started to recognise her mother's voice and face.

Beverly: "She ... shows it with her eyes, ... she watches my face ... to show me she is interested. When she hears my voice she does stop crying" (T1).

At T2, Anathi started recognising voices and reacted differently to each family member.

Abigail: "He knows my voice, he stops crying when I talk. He looks at me too when I talk." (T2).

Later, the mothers observed even more interactions. At T3, Blair was reported to show more interest in other people and objects.

Beverly: "She needs to be entertained a little more. She wants more ... She is very interested in people, like now, she will sit and watch you ..." (T3).

Abigail reported developing the reciprocal relationship with her baby after being discharged from hospital, when she was able to engage in daily interactions. Their early bonding experiences may have been delayed due to the complexities of premature birth and the accompanying emotional strain. The difficulties were less pronounced with the other dyad, but also noted to some extent. Having other children at home may have reduced Beverly's time available to spend with Blair, especially initially, but her previous experiences may also have mediated her anxiety.

Both mothers reported that their infants' activity levels increased considerably over the three visits. At the first visit, both noted that most time was spent sleeping. With the rising activity levels, the infants became more responsive and engaged more with their environment which then promoted better opportunities for interacting.

\subsubsection{Pragmatics}

Both infants made minimal eye contact at T1. Abigail positioned Anathi to encourage eye contact but commented that he rarely looked at her. Beverly described occasional eye contact:

Beverly: "Sometimes in the dark ... you can see her big eyes looking at me" (T1).

Eye contact became better established for both babies at T2. Blair started to indicate interest in objects by focussing her eyes on them.

Beverly: "She is just starting to look at objects, briefly" (T2).

By T3 both babies could maintain eye contact for longer periods of time.

Abigail: "When I talk to him, he ... looks at me and smiles" (T3).

Both infants started turn taking from T1.

Abigail: "... I cough when he is in kangaroo, then he kicks" (T1).

Blair started to engage in vocal turn taking at around T2 while Anathi started at T3.

Beverly: “... she makes noises and then we copy her, then she might do it again” (T2).

Abigail: "He makes noises ... when I sing. I talk to him when he makes noises. I repeat what he says" (T3).

Beverly felt that using babytalk resulted in Blair making more eye contact.

Beverly: "She looks for longer when I babytalk, it is almost as if she is partaking in the conversation for a bit, but she can't"' (T3).

Full-term infants are attracted to visual stimuli within a few hours after birth. Here the infants showed minimal eye contact after birth due to their relatively underdeveloped physical and mental maturity. However, both were maintaining eye contact for prolonged periods of time by T3. These skills are age-appropriate as eye contact is normally established at around one month. As the infants engaged in more 
eye contact, bonding and attachment is also likely to have been enhanced.

Blair started vocal turn taking at T2 and Anathi slightly later, at T3. Vocal turn taking normally develops around 3 months of age, corresponding with $\mathrm{T} 2$ in the current study. It is essential for the development complex speech and conversational skills. The transactional model would suggest that as the infants developed, they started vocalising more, encouraging their mothers to engage in vocal turn taking with them. The mothers and infants might have reinforced one another's vocalisations, establishing early communication.

\subsubsection{Play}

Beverly introduced toys from T1.

Beverly: "She is probably ready to start being entertained by a mobile" (T1).

Abigail, in contrast, felt that her infant was too young to play with toys initially.

Abigail: "He is not playing with toys yet, he is too young. I will give him when he is 6 months. My aunty told me this" (T1).

At T2, both mothers engaged in verbal play with their infants.

Beverly: "If I make noises ... she makes it, then I make it again" (T2).

At T3, Abigail introduced a rattle which Anathi enjoyed shaking. Blair engaged in shaking and banging her toys and explored her environment. She enjoyed interacting with specific toys:

Beverly: "There are a ... toys she prefers, ... the teething thing, soft toys that make a noise, and there is a book ... I often give her while giving her the bottle ... it got that paper inside that when you squash it makes a noise" (T3).

Abigail considered her infant too young to play with toys at $\mathrm{T} 1$ and $\mathrm{T} 2$ and followed her relative's advice in waiting until Anathi was older. Beverly introduced toys at T1. This relatively early introduction of toys could be a result of better financial access to toys and also due to better maternal education. In this study, Beverly was a mother from a relatively high SES with a tertiary level of education. Beverly also had older children so she had ready access to toys.

Anathi started holding and banging toys at T3 (6 months corrected age), skills normally expected to occur at 5 months of age. Blair started holding and banging toys at T2. The low activity levels of the infants as well as the mother's age influenced the introduction of toys, which in turn may have impacted on the infants' play skills.

\subsubsection{Language comprehension}

Both infants started to become aware of sounds and startling to noises at T1. From T2, they started to localize sounds by turning their head in the direction of the noise and were able to discriminate between familiar people's voices and tones of voices.

Beverly: "She looks in the direction of the sound. She looks when we talk to her ..." (T2).

Abigail: "Sometimes I shout at him. He knows I am angry. He is then crying" (T3).

\subsubsection{Language expression}

At $\mathrm{T} 1$, the mothers reported that their infants expressed themselves through crying and made bodily sounds such as burping.

Abigail: "He is crying when he needs a nappy change. He does not make any sounds. He burps after feeding" (T1).

Both infants started cooing at T2 and Blair also interrupted her mother's vocalizations.

Beverly: "I am talking, she interrupts me, and sometimes starts 'talking' quite loud, then sometimes you have to stop talking" (T2).

Blair and Anathi were both babbling by T3.

Beverly: "She started making babababa at around 3 months but I would say she is changing, it is not as random, there are a lot more repetitions in the sounds, she will stick with a sound and keep saying it again" (T3).

Abigail: "He is making sounds like ya ya ya ya" (T3).

The language comprehension skills reported for both infants were age-appropriate. Both had started babbling by T3. Babbling normally emerges between four and six months of age, and is an important precursor to language development.

\subsection{Aim 2: mothers' perceptions of their role in the communication of their premature infants}

Analysis of the interviews generated two main themes: 'physical contact' and 'verbal expression'. These are discussed for both dyads with inclusion of subthemes under each main theme, and illustrated with quotes.

\subsubsection{Theme 1: physical contact}

\section{- Holding}

Abigail wanted to hold Anathi from the time he was born but was only able to when she started KMC, a week after birth.

Abigail: "I could not hold him. I could not play with him, just see him, no holding for one week" (T1).

At T1, Abigail touched and held Anathi throughout the day. As he became older, she started holding him less. 
Abigail: "When he was a baby I held him all the time, now he is bigger I do not hold him as much. I sit him ... on the couch and he is on the floor" (T3).

Beverly held Blair on the day she was born but only for a limited period of time. While still in the NICU, both parents would try to spend time everyday holding her.

Beverly: "They didn't like her to ... be passed around ... rather sit with one person for an hour, ... my husband would hold her for an hour" (T1).

Both mothers practiced KMC after birth but had stopped by T2. Beverly reported that KMC was beneficial to her infant.

Beverly: "they ... get very peaceful when they are on the mother's chest. I think she just kind of gets so relaxed, I can feel her breathing slowing down and her ... muscles just give in" (T1).

\section{- Positioning}

At T1, Abigail used the KMC position and also placed Anathi in her arms. She favoured face-to-face positioning. Beverly preferred placing Blair in her arms during feeding to make sure that she could watch her reactions. At other times, she would place her on her legs, on the couch or next to her on the bed. She also mostly positioned Blair in a face-to-face manner at T1.

Beverly: "I hold her in my arm, in my elbow ... I can see what she is doing and ... can hold her a little ... upright" (T1).

At T2, Blair would sit in her pram and baby seat or lie down. Beverly also placed Blair on her stomach everyday for 'tummy time'. She continued feeding Blair in her arms. At T2, Beverly used a combination of face-to-face and the facing-away position.

Beverly: "If I am talking to her, then she is always like this (face to face) ... then when she gets tired ... I sit her down like this, more on my lap (facing away)" (T2).

By T2, Abigail had stopped KMC but often positioned Anathi on her chest: she felt that he liked that because of his familiarity with KMC. She placed him on her lap during feeding and on the couch when she was busy. At T3, Abigail continued using these positions but also started placing him upright against her shoulders and in a walking ring. At T2 and $\mathrm{T} 3$, she used a combination of face-to-face and side-by-side positioning. At T3, Abigail also reported facing Anathi away from her during certain positions.

Abigail: "I hold him on my lap (facing outwards) or on shoulders. I hold him this way (lap) because he is going to fall" (T3).

\section{- Breastfeeding}

Feeding difficulties can have a negative impact on the bonding process between the mother and her child. Breastfeeding was a challenge for Abigail who would have liked more support from the hospital staff.

Abigail: "I wanted them to show me how to breastfeed ... and they didn't. I had to do it by myself. When I got discharged, my family helped me with feeding ... they told me how to breastfeed him" (T1).

For both mothers, holding their babies formed an important part of the early interaction with their infants. The inability to hold their infants during the early days of their life was perceived to have affected the bonding process, even two months after they had been discharged. Abigail reported that the practice of KMC helped her bond with her infant; Beverly was not so explicit about her use of KMC but also emphasised the importance of holding Blair.

\subsubsection{Theme 2: verbal expression}

- Helping talking

Both mothers noted from the outset that they had an important role to play in developing their child's communication.

Abigail: "He learns by listening to me, that is why I talk to him" (T1).

Beverly: "I think it's quite important to talk to them because ... initially they can't see much ... So they get used to voices before faces ..." (T1).

They used various techniques in order to help their infants communicate. Both mothers used babytalk during their interactions with their infants. Beverly reported that Blair was more responsive and alert to the high-pitched voice used during babytalk.

Beverly: "I'd say that kind of more high-pitched voice, she is ... more alert to, she reacts more to it than just the normal adult voice." (T1).

At T2, Abigail started to repeat Anathi's vocalisations.

Abigail: "If he makes noise, I also play with him and talk to him. I repeat what he says" (T2).

Abigail started engaging in everyday situational talk with Anathi at T2, and continued doing so at T3.

Abigail: "I talk to him, not like I am talking to you, in a baby way. I speak slower, use baby words. I talk to him when I come back from school ... about how school was, and ask him how his day was" (T3). 
By T3, Beverley reported no difference in her interaction with Blair as compared to her other children at similar ages.

Beverly: "I don't think I react differently to her now, not anymore. I think I have almost forgotten that she was born prematurely" (T3).

Beverly: "If she is making happy noises, I will make it with her ... or make other ones, make it almost like a conversation." (T3).

\section{- Singing}

Singing was an important part of verbal expression for both dyads. Beverly reported that she and her other daughters would sing to Blair at T2 and T3.

Beverly: "I ... sing to her, if she is crying, I sing and the kids sing." (T2).

Beverly: "I sing to her to calm her down ... at night" (T3).

Similarly, Abigail reported that she preferred singing to Anathi, and spoke of their mutual enjoyment of isiXhosa lullabies.

Abigail: "I sing to him ... baby Xhosa songs" (T3).

- Increase in communication

At T3, both mothers reported engaging more with their infants once they were more responsive.

Abigail: "I talk more ... he is more mature now. Before I spoke but not much because he doesn't respond" (T3).

Beverly: "My role has changed because the more engaging she becomes, the more we do" (T3).

The participants reported using simple techniques such as modelling at $\mathrm{T} 1$, and more complex techniques such as copying, labelling and expansions with time. Abigail only used modelling and copying at T3. She did not engage in expanding her infants' vocalisations. She reported engaging in conversations only when her infant was more alert, at T2. Anathi developed vocal turn taking skills at T3, compared to the other infant who started at T2. The transactional model can be used to explain these changes in interactional patterns. As Anathi grew, he started becoming more alert and reacted more to his mother's attempts to converse with him. Abigail in turn started to encourage conversation more often (at T2) as she became more confident. As Anathi's speech became more developed (at T3), Abigail started engaging in vocal turn taking activities.

\section{Discussion}

This study focused on the perceptions of mothers regarding communication of, and with, their premature infants. Abigail was a teenager, and from a relatively low SES background. Beverly was a married woman, in her thirties who already had two older children. She lived in a more affluent part of the city, and had a tertiary qualification. Despite these differences, the mothers' perceptions of their infants' communication and their own role in communication, were similar. Both noted similar concerns and challenges with early bonding. They both had a strong awareness of the importance of their role in communication development, and used similar strategies (some physical and some relating to verbal expression) to encourage communication. Similarly, the outcomes for the infants were similar. Attachment did occur for both pairs and both babies achieved expected communication milestones in the first year of life.

Some of the differences in the mothers' worldviews were illustrated by their attitude to toys. Abigail introduced toys at a later stage in her infant's development since a family member had informed her that it was not appropriate to do this too soon. Beverly produced these early on for her baby believing that early stimulation was important. As Beverly already had two children and there would have been toys in the house already, as well as more disposable income, this may also have influenced her attitude to producing toys early. Despite these possible cultural/contextual differences, what should be noted is that while the nature of the play differed, both mothers described playing with their infants and encouraging play, albeit in slightly different ways and with different tools.

Maternal age, education and SES have been reported to have an impact on mother-infant interactions and child development (Lewis et al., 2002). Rowe, Pan, and Ayoub (2005) stated that older mothers tend to be more responsive, provide more and richer talk with their infants. Piccinini, Tudge, Marin, Frizzo, and Lopes (2010) reported that mothers from higher SES talk more and interpret their 3-month-old infants' behaviours more than mothers from a lower SES. In the current study, Beverly, an experienced mother, with a tertiary level of education and from a higher SES could have been more aware of communication development and thus showed optimal patterns of communicating with her infant from the first visit. She may also have felt more comfortable being observed and been more familiar with the nature of research, hence was less inhibited by the researcher's presence. Abigail, used less complex forms of speech during interaction. Giardino, Gonzalez, Steiner, and Fleming (2008) note that teenage mothers may be less responsive due to their emotional immaturity and inexperience with child rearing.

Both mothers reported using 'babytalk,' modified, simplified adult talk, with their infants. The literature regarding the use of babytalk is inconsistent. Falk (2004) reported that infants prefer babytalk (BT) over adult-directed speech (ADS), a way of talking that does not show specific modifications for children. Bendixen and Pelaez (2010) found that the use of BT resulted in higher canonical babbling in a 12-month old infant. These findings indicate that specific maternal vocal styles play an important role in shaping early development of infant speech.

The transactional model takes into account various risk and protective factors within the child's environment. The transactional model suggests that each family comprises of its own risk factors and protective factors which result in unique 
developmental outcomes for the child. The one dyad studied here presented with two risk factors (low SES and premature birth), but showed similar mother-infant interaction patterns as the dyads with one risk factor only (premature birth). This indicates that the quality of the early mother-child relationship could have a protective role on the communication development of the infants. Fig. 2 depicts the relationship between the risk factors and protective factors found in this study and their possible effects on mother-infant interaction as well as child development.

\subsection{Clinical implications}

Speech and language therapists are concerned with communication development and place a strong emphasis on early intervention. Addressing a child's communication difficulties can ameliorate the difficulties and save time and money over the long term. Therapists working with young children are concerned not only with the child themselves but also with the caregivers and the relationship between child and carers. Supporting and addressing this relationship - although fairly straightforward in many cases - can have a great impact on a child's subsequent development (Rossetti, 2001). The model shown in Fig. 1 could be a useful way for health professionals to conceptualise ways to achieve optimal communication development when working with families. This model is not static: bringing about small changes (e.g. introducing KMC, developing attachment, talking more to an infant) can have large effects on the entire system and ultimately the child's communication development.

It is important for SLPs to learn more about the communication development of premature infants, especially due to the high prevalence of premature infants in South Africa (McInroy \& Kritzinger, 2005). SLPs are required to provide culturally appropriate information and support to the parents of the premature infant. In order to do so, SLPs need to become more knowledgeable by carrying out research pertaining to the communication development of infants in the NICU and after discharge. The information obtained in this study may

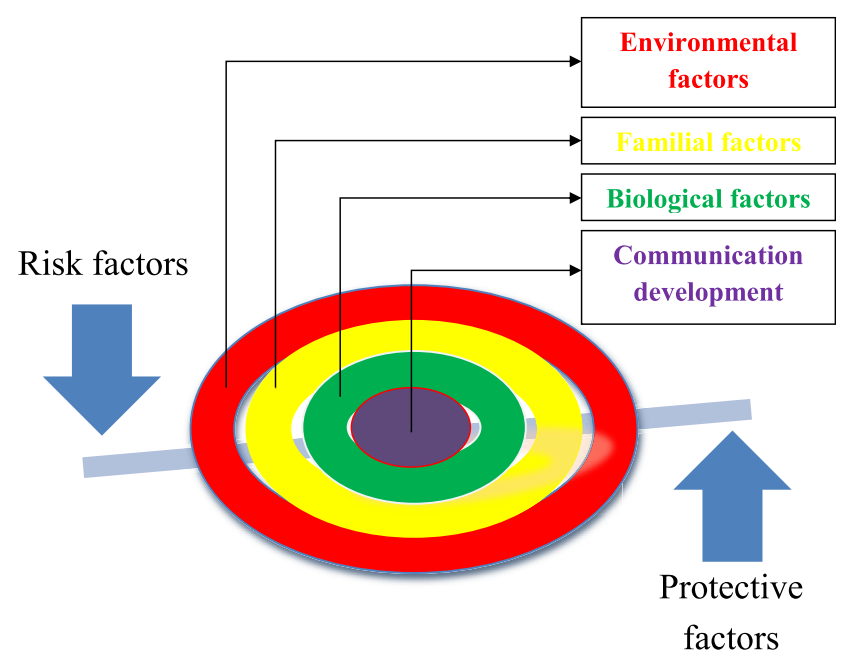

Fig. 2 - Transactional model in mother-preterm infant interaction and communication development. contribute to the way in which SLPs make specific recommendations during their contact with premature infants and their families.

The most important clinical implication of this study would be to support a healthy mother-infant relationship in the first few months of life. SLPs could use the transactional model as a framework during assessment and intervention. For example, parents could be provided with information on how premature birth could potentially have an impact on their interaction with their infant and on his or her communication development. The transactional model could be used to show parents how different risk and protective factors interact with each other in determining each infant's outcomes.

\subsection{Limitations}

This study only included two mother-infant dyads. The results cannot be generalised due to the small sample size. Inclusion of objective measures would provide a further dimension to the study. However, the qualitative data regarding mothers perceptions was felt to be important, and there is a growing body of research that has forefronted mothers' perceptions of their infants and experiences around birth (Finlayson, Dixon, Smith, Dykes, \& Flacking, 2014; Nesbitt et al., 2012).

\section{Conclusions}

This research provided in-depth information about motherpremature infant communication from the mothers' perspective. The premise of this study is the importance of early communication for later communication development and the transactional nature of the mother-infant relationship. The data obtained from this project provides valuable information that could be incorporated into counselling, health promotion, early identification and management of premature infants and their families.

\section{Appendix. Interview Schedules}

\section{T1: one week post discharge from NICU}

1. Tell me what happened from the time you were admitted to hospital until 'name of infant-X' was discharged?

- X's birth

- Medical status of X

- Feelings about having a premature baby

- Bonding and attachment (holding and interacting with X)

- Kangaroo Mother Care

- Support from others (family and health professionals)

- Information obtained from health professionals (medical, feeding, development, including communication)

2. How did you feel when $\mathrm{X}$ was discharged from hospital?

- Happy/overwhelmed/not ready 
3. What happened when $\mathrm{X}$ was discharged from hospital?

- Support at home

- Taking care of other child (if applicable)

4. How do you and $\mathrm{X}$ interact?

- Positioning (baby in cot, face-to-face, on mom's lap, on floor, etc)

- Cuddling, touch

- Special moment with baby-feeding, changing nappy

- How you spend most of your day

5. How does $\mathrm{X}$ interact with others (significant carers and siblings)?

6. How active is $\mathrm{X}$ ?

- Different states of alertness

- Sleeps most of the time/cries a lot

- Watches mom during feeding, talking, etc

- Mother and baby routines

7. How does $X$ react to different sounds in the environment?

- No reaction, turns towards sound

- Looks surprised/gets a fright in response to loud noise

8. How does X express himself/herself for different needs? (for example when hungry v/s when needs nappy change)

- Cries for help

- Different types of cries

- Makes body sounds (such as burping)

9. How do you and other people (siblings, father) talk to X?

- Do not talk

- Speak normally-like speaking to older child or adult

- Speak in a baby manner (slow, simple words)

10. How does he/she show that he/she is interested and listening?

- Looks at you

- Stops crying

11. What roles do you feel you play in helping X develop his/ her communication skills (can give examples)?

- To act as a model

- X learns by listening to other children

- $\mathrm{X}$ is too young to learn

12. Is there anything else that you think is important for me to know about X's communication development?

\section{T2: three months corrected age}

1. Tell me what has changed since we last met?

- Relationship with X

- X's development (motor, feeding, communication)

- Support at home

- Any issues raised in interview 1

2. How do you and $X$ interact?

- Positioning (floor, chair, lap)

- Face-to-face (some eye contact), side-to-side

- Holds X when cries, sleep, etc

- Make noises in turns (turn taking), he/she tries to copy mom

- Make funny faces

- Look at same object together (joint attention) when placed in front of $\mathrm{X}$

- When do you spend most of your time interacting (feeding, nappy change, etc)
- Why do you prefer this type of interaction?

3. How does $\mathrm{X}$ interact with others (father, caregiver, siblings)

4. How does X play with toys?

- Plays with a rattle

- Smiles and laughs

- Cries

- Favourite toy

5. How does $\mathrm{X}$ react to loud noises?

- Does not respond, Cries, Looks away, Looks where the sound is coming from

6. How does $\mathrm{X}$ respond when you talk to him/her?

- No reaction/ignores you, Look at you (eye contact), Turn away, Smiles, laughs

Recognises your voice, Tries to make sounds in response (vocal turn taking), Quiets if was crying.

7. How does $\mathrm{X}$ show you that he/she needs something?

- Cries-different

- Makes sounds (describe types)

8. What do you do in response to $\mathrm{X}$ making noises?

- Ignore it

- Change the topic

- Copy the sounds

- Copy and add words (expand)

9. Thinking back to your older child, how does X compare to his/her older sister/brother? (if applicable)

- Interaction with mom (bonding, attachment, eye contact, joint attention, emotions, turn taking)

- Reactions to sound and voice

- Playing with toys

- Noises that he/she makes

10. What roles do you feel you play in helping $\mathrm{X}$ communicate?

- Mother-talks the most, gives the example (model)

- Need to provide further stimulation as child is premature

- X learns from others

- $\mathrm{X}$ not ready to communicate

11. Generally, how do you communicate with $\mathrm{X}$ ?

- Do not talk to X, too young

- Speak normally-like speaking to older child or adult

- Speak in a baby manner (slow, simple words)

- Songs and rhymes

12. Is there anything else that you think is important for me to know about X's communication development?

\section{T3: six months corrected age}

1. Tell me what has changed since we last met?

- Relationship with X

- X's development (motor, feeding, communication)

- Any issues raised in interview 2

- Started working

2. How do you and $\mathrm{X}$ interact now?

- Positioning (floor, chair, lap)

- Face-to-face (eye contact-how long?), side-to-side

- Holds X (when cries, during feeding etc)

- Make noises in turns (turn taking), he/she tries to copy mom 
- Make funny faces-baby tries to copy

- Look at same object together (joint attention) - child looks for object

- When do you spend most of your time interacting (feeding, nappy change, etc)

- Why do you prefer this type of interaction?

3. How does $\mathrm{X}$ interact with others (father, caregiver, siblings)?

4. How does X play with toys?

- Smiles and laughs when plays alone

- Cries

- Likes to explore environment, and play with different objects-reaches out

- Bangs toy

- Looks at self in mirror

- Favourite toy

5. How does $\mathrm{X}$ respond when you talk to him/her?

- No reaction/ignores you

- Looks at you for long (eye contact)

- Turns away

- Smiles, stops crying

- Tries to make sounds in response (vocal turn taking)

- Knows own name

- Has started responding to 'no'

- Knows different voices

6. How does $\mathrm{X}$ show you that he/she needs something?

- Cries-different

- Makes sounds (babbling-bababa)-in turns

- Vocalises when hears songs

- Uses different volumes, pitch and rate

7. What do you do in response to $\mathrm{X}$ making noises?

- Ignore it

- Change the topic

- Copy the sounds

- Copy and add words (expand)

8. Thinking back to your older child, how does X compare to his/her older sister/brother? (if applicable)

- Interaction with mom

- Reactions to sound and voice

- Playing with toys

- Noises that he/she makes

9. How has your role in helping $\mathrm{X}$ communicate changed over time?

- Mother-talks more now

- Other people also talk

- More complex patterns of speech

10. Generally, how do you communicate with $\mathrm{X}$ ?

- Speak normally-like speaking to older child or adult

- Speak in a baby manner (slow, simple words)

- Songs and rhymes

11. Is there anything else that you think is important for me to know about X's communication development?

\section{R E F E R E N C E S}

Allen, E. C., Manuel, J. C., Legault, C., Naughton, M., Pivor, C., \& O'Shea, T. M. (2004). Perception of child vulnerability among mothers of former premature infants. Pediatrics, 113, 267-273.
Bairati, I., Meyer, F., Gueye, C., Desmarais, C., Rouleau, N., \& Sylvestre, A. (2011). Factors influencing parent satisfaction with preventive health services for the early detection of speech and language delay in preschool children. Open Journal of Preventive Medicine, 1(3), 135-142.

Bendixen, M. I., \& Pelaez, M. (2010). Effects of contingent maternal imitation vs. Contingent motherese speech on infant canonical babbling. In M. S. Plakhotnik, S. M. Nielsen, \& D. M. Pane (Eds.), Proceedings of the Ninth Annual College of Education \& GSN Research Conference (pp. 2-6). Miami: Florida International University. http://coeweb.fiu.edu/research_ conference/.

Borghini, A., Pierrehumbert, B., Miljkovitch, R., Muller-Nix, C., Forcada-Guex, M., \& Ansermet, F. (2006). Mothers' attachment representations of their premature infant at 6 and 18 months after birth. Infant Mental Health Journal, 27, 494-508.

Briscoe, J., \& Gathercole, S. E. (2001). Everyday memory and cognitive ability in children born very prematurely. Journal of Child Psychology and Psychiatry, 46, 749-754.

Crosbie, S., Holm, A., Wandschneider, S., \& Hemsley, G. (2011). Narrative skills of children born preterm. International Journal of Language and Communication Disorders, 46, 83-94.

Falk, D. (2004). Prelinguistic evolution in early hominins: whence motherese? Behavioral and Brain Sciences, 27, 491-541.

Finlayson, K., Dixon, A., Smith, C., Dykes, F., \& Flacking, R. (2014). Mothers' perceptions of family centred care in neonatal intensive care units. Sexual and Reproductive HealthCare. http:// dx.doi.org/10.1016/j.srhc.2014.06.003.

Giardino, J., Gonzalez, A., Steiner, M., \& Fleming, A. S. (2008). Effects of motherhood on physiological and subjective responses to infant cries in teenage mothers: a comparison with non-mothers and adult mothers. Hormones and Behavior, 53, 149-158.

Keilty, B., \& Freund, M. (2005). Caregiver-child interaction in infants and toddlers born extremely premature. Journal of Pediatric Nursing, 20, 181-189.

Kritzinger, A., \& Louw, B. (2003). Clinical training of undergraduate communication pathology students in neonatal assessment and neonate-caregiver interaction in South Africa. The South African Journal of Communication Disorders, 50, 5-14.

Leigh, J., Dettman, S., Dowell, R., \& Briggs, R. (2013). Communication development in children who receive a cochlear implant by 12 months of age. Otology \& Neurotology, 34, 443-450.

Leonard, A., \& Mayers, P. (2008). Parents' lived experience of providing Kangaroo mother care to their preterm infants. Health SA Gesondheid, 13(4), 16-28.

Lewis, B. A., Singer, L. T., Fulton, S., Salvator, A., Short, E. J., Klein, N., et al. (2002). Speech and language outcomes of children with bronchopulmonary dysplasia. Journal of Communication Disorders, 35, 393-406.

Limperopoulous, C., Bassan, H., Sullivan, N. R., Soul, J. S., Robertson, R. L., Moore, M., et al. (2008). Positive screening for autism in ex-preterm infants: prevalence and risk factors. Pediatrics, 121, 758-765.

McInroy, A., \& Kritzinger, A. (2005). A single case study of the communication development of a high-risk neonate, from birth to discharge from a NICU. The South African Journal of Communication Disorders, 52, 25-35.

Montirosso, R., Borgatti, R., Trojan, S., Zanini, R., \& Tronick, E. (2010). A comparison of dyadic interactions and coping with still-face in healthy pre-term and full-term infants. British Journal of Developmental Psychology, 28, 347-368.

Muller-Nix, C., Forcada-Guex, M., Pierrehumbert, B., Jaunin, L., Borghini, A., \& Ansermet, F. (2004). Prematurity, maternal stress, and mother-child interactions. Early Human Development, 79, 145-158. 
Nesbitt, S., Campbell, K., Jack, S., Robinson, H., Piehl, K., \& Bogdan, J. (2012). Canadian adolescent mothers' perceptions of influences on breastfeeding decisions: a qualitative descriptive study. BMC Pregnancy and Childbirth, 12, 149.

Piccinini, C. A., Tudge, J., Marin, A. H., Frizzo, G. B., \& Lopes, R. S. (2010). The impact of socio-demographic variables, social support, and child sex on mother-infant and father-infant interaction. Interamerican Journal of Psychology, 44, 203-212.

Porter, J. S., Stern, M., \& Zak-Place, J. (2009). Prematurity stereotyping and perceived vulnerability at 5-months: relations with mothers and their premature and full-term infants at 9-months. Journal of Reproductive and Infant Psychology, 27(2), 168-181.

Rossetti, L. M. (2001). Communication intervention: Birth to three (2nd ed., p. 305). Oshkosh: Singular Thomson Learning.

Rossetti, L. M. (2005). The Rossetti Infant-Toddler Language Scale: Examiner's manual (p. 167). East Moline: LinguiSystems, Inc..

Rowe, M. L., Pan, B. A., \& Ayoub, C. (2005). Predictors of variation in maternal talk to children: a longitudinal study of lowincome families. Parenting: Science and Practice, 5, 285-310.

Sameroff, A. J., \& Fiese, B. H. (2000). Transactional regulation: the developmental ecology of early intervention. In Handbook of early childhood intervention (Vol. 2, pp. 135-159). Cambridge University Press.

Singer, L. T., Fulton, S., Davillier, M., Koshy, D., Salvator, A., \& Baley, J. E. (2003). Effects of infant risk status and maternal psychological distress on maternal-infant interactions during the first year of life. Journal of Developmental \& Behavioral Pediatrics, 24, 233-241.

Suttora, C., \& Salerni, N. (2011). Maternal speech to preterm infants during the first 2 years of life: stability and change. International Journal of Language \& Communication Disorders, 46, 464-472.

Swift, M. C., \& Scholten, I. (2009). Not feeding, not coming home: parental experiences of infant feeding difficulties and family relationships in a neonatal unit. Journal of Clinical Nursing, 19, 249-258.

Tallandini, M. A., \& Scalembra, C. (2006). Kangaroo mother care and mother-premature infant dyadic interaction. Infant Mental Health Journal, 27, 251-275.

Terre-Blanche, M., Durrheim, K., \& Painter, D. (2006). Research in practice: Applied methods for the social sciences (p. 594). Cape Town: University of Cape Town Press.

Van Rie, A., Mupuala, A., \& Dow, A. (2008). Impact of the HIV/AIDS epidemic on the neurodevelopment of preschool-aged children in Kinshasa, Democratic Republic of the Congo. Pediatrics, 122(1), 123-128.

Veddovi, M., Kenny, D. T., Gibson, F., \& Starte, D. (2001). The relationship between depressive symptoms following premature birth, mothers' coping style, and knowledge of infant development. Journal of Reproductive and Infant Psychology, 19, 313-323.

World Health Organisation (WHO). (2014). Preterm birth: FactSheet No.363 Accessed 23.07.14. http://www.who.int/mediacentre/ factsheets/fs363/en/ 